\title{
Brief Report: The Relationship between Discourse Deficits and Autism Symptomatology
}

\author{
Courtney M. Hale ${ }^{1}$ and Helen Tager-Flusberg ${ }^{2,3}$
}

\begin{abstract}
This study investigated the relationship between discourse deficits to a broader range of other symptoms in 57 children with autism. We hypothesized that autism symptomatology, as measured by the Autism Diagnostic Observation Schedule (ADOS), would be related to the children's difficulty in maintaining an ongoing topic of discourse. Children provided a natural language sample while interacting with one parent. These language samples were coded for the child's use of off-topic or noncontingent utterances. Results showed significant relationships between overall diagnostic symptomatology, and more specifically, deficits in communication as measured by the ADOS-G, and noncontingent discourse. The findings provide diagnostic validity to the ADOS-G and highlight in greater detail the significant communication impairment in autism.
\end{abstract}

KEY WORDS: ADOS; autism; communication; discourse.

According to DSM-IV (APA, 1994), one of the defining characteristics of autistic disorder includes a qualitative impairment in communication. The key universal deficits are in pragmatics - the ability to effectively use language in a range of social contexts (Lord \& Paul, 1997; Tager-Flusberg, 1996, 2000). Children with autism demonstrate a variety of conversational deficits that hinder or limit their discourse skill. They experience difficulty conforming to conversational rules such as initiating and engaging in reciprocal conversations (Baltaxe, 1977; Loveland \& Landry, 1986; Ramberg, Ehlers, Nyden, Johansson, \& Gillberg, 1996; Stone \& Caro-Martinez, 1990; Tager-Flusberg, 1999). A lack of conversational management skills is illustrated by an

\footnotetext{
${ }^{1}$ Department of Psychiatry, Children's Hospital, Harvard Medical School, USA.

${ }^{2}$ Boston University, School of Medicine, USA.

${ }^{3}$ Correspondence should be addressed to: Helen Tager-Flusberg, Department of Anatomy and Neurobiology, Boston University School of Medicine, 715 Albany Street, L-814 Boston, MA 021182526, USA; Fax: +1-617-414-1301; e-mail: htagerf@bu.edu
}

inability to maintain a conversation following a listener's answer to a question and to engage in effective turn-taking (Hurtig, Ensrud, \& Tomblin, 1982; Prizant \& Rydell, 1993). Moreover, children with autism are less likely to respond to requests for clarification in a conversation and exhibit an impaired ability to repair their messages by being informative (Geller, 1998; Paul \& Cohen, 1985). They also have problems making clear reference during conversations with others (Fine, Bartolucci, Szatmari, \& Ginsberg, 1994).

An important area of investigation examines the content of conversational discourse by looking at offtopic or noncontingent utterances. A noncontingent utterance, as defined by Tager-Flusberg and Anderson (1991), is an utterance that does not relate to the topic of the prior speaker's utterance. Noncontingent utterances, which disrupt the flow of conversation, may take different forms. For example, Volden and Lord (1991) reported that autistic children use neologisms and idiosyncratic language significantly more than age- and language-matched controls. They are often characterized as having a rigid and stereo- 
typed use of language, in which a word or phrase is used in limited contexts and verbal routines are used to serve communicative needs (Loveland, Landry, Hughes, \& Hall, 1988). Thus, noncontingent discourse may be partially attributed to a tendency to use scripted or idiosyncratic speech, which by definition is unrelated to the social, communicative context in which the child is engaged. Volden, Mulcahy, and Holdgrafer (1997) found that children with autism produced a greater number of unusual utterance features and interrupted the flow of the interaction with more inappropriate statements, in comparison to age-matched normally developing controls. Finally, Adams and her colleagues (Adams, Green, Gilchrist, \& Cox, 2002) found that adolescents with autism spectrum disorder provided more tangential and inadequate responses in conversation with an examiner, especially when discussing personal events.

Only a small number of empirical studies have focused on quantitative objective measures of the discourse deficits that characterize autistic disorder. Through the use of a hierarchical coding scheme of contingent discourse, Tager-Flusberg and Anderson (1991) compared spontaneous speech samples of six children with autism with the speech samples of six children with Down syndrome. They identified specific deficits in reciprocal conversation that were defined as failure to respond to adult initiations, responding in a noncontingent or non-topically related way, or failure to expand the ongoing topic. Using a similar coding scheme, Capps, Kehres, and Sigman (1998) found that children with autism failed to respond to questions appropriately, and that the discourse deficits were related to performance on a false belief task.

This brief review highlights the significance of conversational deficits in autism. However, it is not known whether these specific deficits relate to the overall symptomatology, and diagnostic classification, of the disorder. This study was designed to address this question, using the Autism Diagnostic Observation Schedule (ADOS; Lord et al., 2000). The ADOS provides objective measures of core social and communicative impairments in autism spectrum disorders. Through the use of a semi-structured interactive observation with a trained clinician, the assessment involves a set of social occasions and "presses" designed to elicit behaviors relevant to a diagnosis of autism. We hypothesized that other aspects of communication and social interaction that are characteristically disordered in autism, as assessed by the ADOS, would be significantly related to the children's inability to maintain an ongoing topic of discourse.

\section{METHODS}

\section{Participants}

The participants for this study included 57 children with autism ranging in age from $4 ; 0$ to $13 ; 11$. They were selected on the basis of having at least some language, defined as the ability to use phrase speech (at least some multi-word utterances). Children were diagnosed using DSM-IV criteria, using algorithm scores on the Autism Diagnostic InterviewRevised (ADI-R; Lord, Rutter, \& LeCouteur, 1994) and the ADOS (Lord et al., 2000) and confirmed by an expert clinician. All the children in the study met ADI-R criteria for autism. On the ADOS, 50 children met criteria for autism, 5 for autism spectrum disorder, and 2 children failed to meet criterion on the algorithm items, missing by one point. The ADI$\mathrm{R}$ and ADOS were administered by trained personnel who had demonstrated reliability in scoring with the authors of the instruments and on-site trainers. Children with Rett syndrome, Childhood Disintegrative Disorder, or with autism-related medical conditions (e.g., neurofibromatosis, tuberous sclerosis, Fragile-X syndrome) were not included in this study. Details about the participants are presented in Table I.

\section{Measures}

Cognitive ability: IQ level was assessed with the Differential Ability Scales (DAS; Elliott, 1990). The DAS yielded a full scale IQ, and verbal and nonverbal subscores for children tested within age level.

Language: Two standardized measures of vocabulary were obtained: the Peabody Picture Vocabulary Test, Third Edition (PPVT-III; Dunn \& Dunn, 1997), which measures receptive vocabulary, and the Expressive Vocabulary Test (EVT; Williams, 1997), which measures expressive vocabulary. Because scores on the PPVT-III and EVT are highly correlated, and the tests were developed on the same normative sample, we combined the scores on these tests to yield a single combined vocabulary score.

Table I. Participant Characteristics

\begin{tabular}{llll}
\hline & $M$ & \multicolumn{1}{c}{ SD } & Range \\
\hline Age in years; months & $7 ; 5$ & $2 ; 5$ & $48-167$ \\
Full scale IQ score & 77.47 & 19.19 & $42-118$ \\
PPVT-III standard score & 77.14 & 20.88 & $40-134$ \\
EVT standard score & 75.08 & 21.91 & $40-136$ \\
\hline
\end{tabular}


Table II. Correlations between ADOS, Noncontingent Discourse and Related Variables

\begin{tabular}{lccc}
\hline & ADOS total & ADOS social & ADOS communication \\
\hline Noncontingent Discourse & $.39^{*}$ & $.33^{*}$ & $.40^{* *}$ \\
Vocabulary score & $-.31^{*}$ & $-.38^{* *}$ & $-.55^{* *}$ \\
Full Scale IQ & -.23 & $-.34^{* *}$ & $-.49^{* *}$ \\
Age & -.19 & -.11 & $-.32^{*}$ \\
\hline$* p<.05 ; * p<.01$. & & &
\end{tabular}

\section{Natural Language Samples}

Natural language samples were collected from the children while they interacted with one of their parents (almost always the mother) for 30 minutes in the laboratory. The children and parents were provided with a standard set of toys. Participants were asked to play and interact with each other as they would at home. The session was video- and audiorecorded.

\section{Transcription}

The language samples were transcribed using the SALT transcription format (Miller \& Chapman, 2000) by a team of research assistants trained in transcription procedures. Utterance segmentation and the identification of bound morphemes were based on the guidelines specified by Miller and Chapman (2000). Transcripts were prepared by one person and checked by a second trained transcriber using both the audio- and video-recordings. All transcription disagreements were resolved through consensus. After omitting the first 10 child utterances from the transcript, a corpus of 100 consecutive, complete and intelligible (clear enough to be transcribed) child utterances was selected for analysis. Since children with autism rarely have significant problems with articulation, and this group generally had articulation scores within the normal range (Kjelgaard \& Tager-Flusberg, 2001) few utterances were omitted because they were unintelligible. Thus, the language samples were generally highly representative of the children's overall language use within this conversational setting.

\section{Discourse Coding}

The transcripts were coded for use of topic noncontingent discourse using a coding scheme adapted from Tager-Flusberg and Anderson (1991). Each intelligible child utterance that immediately followed a parent utterance was coded as noncontingent, contingent, or imitation. Noncontingent was defined as child utterances that were not related to the topic of the prior adult utterance. Contingent utterances were defined as maintaining the topic of discourse in the parent's prior utterance. Utterances that were exact or partial imitations of the parent's prior utterance were coded separately. The proportion of child intelligible utterances directly following a parent utterance that were noncontingent, contingent or imitation was computed for each transcript.

Two individuals were trained by the primary coder to assess reliability. Training included the completion of several practice transcripts for which the reliability coder received feedback. The reliability coder had to achieve $80 \%$ agreement with the primary coder on practice transcripts in order to begin reliability coding. Each reliability coder coded 10 randomly selected transcripts representing about $20 \%$ of the transcripts. Reliability was assessed using Cohen's (1960) kappa and percent exact agreement.

Table III. Summary of Hierarchical Regression Analysis Predicting ADOS Total Score from Noncontingent Score

\begin{tabular}{lcccc}
\hline Variable & $\mathrm{B}^{a}$ & $\mathrm{SE} \mathrm{B}^{a}$ & $\mathrm{~B}^{b}$ & $R^{2}$ or $R_{\text {change }}^{2}$ \\
\hline Step 1 & & & & .29 \\
$\quad$ Vocabulary score & 4.18 & .02 & .30 & \\
$\quad$ Full Scale IQ & 4.24 & .02 & .21 & $.05^{*}$ \\
Step 2 & & & & \\
$\quad$ Noncontingent discourse & 9.35 & .43 & .25 & \\
\hline${ }^{*} p .05$. & & & \\
${ }^{a}$ Unstandardized Beta coefficient. & & &
\end{tabular}


Table IV. Summary of Hierarchical Regression Analyses Predicting (a) ADOS Social Score and (b) ADOS Communication Scores from Noncontingent Discourse

\begin{tabular}{|c|c|c|c|c|}
\hline Variable & $\mathrm{B}^{a}$ & $\mathrm{SE} \mathrm{B}{ }^{a}$ & $\mathrm{~B}^{b}$ & $R^{2}$ or $R_{\text {change }}^{2}$ \\
\hline \multicolumn{5}{|l|}{ (a) ADOS social score } \\
\hline \multicolumn{5}{|l|}{ Step 1} \\
\hline Vocabulary score & 1.81 & .01 & .22 & \multirow[t]{2}{*}{.16} \\
\hline Full Scale IQ & 1.85 & .01 & .15 & \\
\hline \multicolumn{5}{|l|}{ Step 2} \\
\hline Noncontingent discourse & 4.65 & .02 & .21 & .04 \\
\hline \multirow{2}{*}{\multicolumn{5}{|c|}{$\begin{array}{l}\text { (b) ADOS communication score } \\
\text { Step } 1\end{array}$}} \\
\hline & & & & \\
\hline Vocabulary score & 9.95 & .01 & .13 & \multirow[t]{3}{*}{.35} \\
\hline Full Scale IQ & 3.65 & .01 & .35 & \\
\hline Age & 1.33 & .01 & .19 & \\
\hline \multicolumn{5}{|l|}{ Step 2} \\
\hline Noncontingent score & 4.56 & .02 & .24 & $.05 *$ \\
\hline
\end{tabular}

Mean Kappa ranged from .88 to 1 , and \% agreement ranged from .80 to 1 .

\begin{abstract}
ADOS
Children in the current study were administered either Module 2 (for children who use phrase speech but are not verbally fluent) or Module 3 (for children who are verbally fluent). Each module includes a standardized diagnostic algorithm composed of a subset of the social and communicative behaviors rated by a trained clinician. Behavioral ratings (e.g., stereotyped/idiosyncratic words or phrases) are based on a hierarchy of mutually exclusive operational definitions corresponding to the following codes: $0=$ not autistic; 1 = atypical, but not clearly autistic; 2 = autistic. In this study we used the total algorithm score, as well as the algorithm scores for the social and communication domains as measures of autism symptomatology. As such, these variables reflect the totality of a multidimensional measure of communication and social interaction symptoms, which is based on a range of observed behaviors empirically established to discriminate between children with and without autism.
\end{abstract}

\section{RESULTS}

Table 2 presents the correlations between the ADOS scores, noncontingent discourse and the descriptive measures for the children in the study. To examine the relationship between noncontingent discourse and autism symptomatology we conducted a series of hierarchical, linear regression analyses predicting to ADOS scores.

The first regression analysis investigated whether noncontingent discourse was a significant independent predictor of ADOS total score (see Table 3). The first step of the analysis included the control variables, IQ and Vocabulary. For Step $1, R^{2}=.29$, $F(2,52)=11.23$. At the second step, noncontingent discourse was entered, $R_{\text {change }}^{2}=.05, \quad \mathrm{M} F$ $(1,51)=4.75, p<.05$, accounting for an additional $5 \%$ of the variance in ADOS total score. Children with autism who produced a greater percentage of noncontingent utterances scored higher on the ADOS reflecting the presence of several other autism symptoms.

In follow-up regression analyses we investigated whether noncontingent discourse was a significant independent predictor of ADOS Social and ADOS Communication scores. The results of these analyses are presented in Table $4 \mathrm{a}$ and $\mathrm{b}$. These analyses show that noncontingent discourse was significantly related to ADOS Communication, contributing an additional 5\% variance, but not to ADOS Social.

\section{DISCUSSION}

This study examined a key area of discourse impairment in autism: the tendency to respond in conversation in an off-topic or noncontingent manner. We hypothesized that a quantitative measure of 
this characteristic of discourse in autism would be significantly related to core aspects of autism symptomatology. Results revealed a significant relationship between the overall deficits that characterize autism, as measured by the ADOS, and noncontingent discourse. A comparison of the ADOS Communication and Social Algorithm Scores further indicated that impairment in the domain of communication, but not social interaction, was significantly related to noncontingent discourse, independent of more general language skills.

Given the mutual dependence of responding appropriately to a conversational partner and overall competence in social communication, we suspect that this significant relationship reflects a common underlying deficit that accounts for difficulties in understanding and using language to interact with others. For example, many researchers have posited the theory of mind hypothesis of autism to explain both the social and language impairments that are at the heart of the disorder (Baron-Cohen, 1988; Frith, 1989; Happé, 1994). The lack of a relationship between impairments in social interaction and noncontingent discourse, once language skills are controlled for, suggests the possibility that discourse distinguishes between the underlying factors for these separate domains of impairment. In other words, the relationship between noncontingent discourse and other autism communication symptoms may derive from theory of mind deficits, whereas deficits in social interaction may relate to other underlying factors that are independent from language. One possibility is that social deficits are more closely related to attentional and perceptual components of social information processing (e.g., Klin, Jones, Schultz, Volkmar, \& Cohen, 2002; Tager-Flusberg, 2001). Future research is needed to examine factors that may distinctively characterize these diagnostic domains.

Our findings also provide diagnostic validity to the ADOS. Children who were rated by a clinician in this structured diagnostic interview as impaired in the communication domain evidenced similar impairment within the context of the natural language sample. Interestingly, the communication domain of the ADOS contains several different items in addition to engagement in reciprocal conversation, such as amount of social overtures, use of stereotyped/idiosyncratic words or phrases, pointing to express interest, use of gestures and reporting of events. Our findings indicate that children who have greater difficulty sustaining an ongoing topic of conversation also show more severe impairments in communication defined more broadly. Across two contrasting conversational partners (a clinician versus parent) and two contrasting contexts (a structured interview versus an unstructured play interaction), children with autism evidenced this conversational impairment. The DSM-IV includes the following diagnostic criteria for autistic disorder: "marked impairment in the ability to initiate or sustain a conversation with others" (APA, 1994, p. 70). These findings add to our knowledge of autism by specifying in greater detail the nature of this impairment, highlighting the distinct use of noncontingent utterances in children with autism and demonstrating the pervasiveness of this defining feature across settings and conversational partners.

Given the persistent nature of this impairment, diagnostic evaluations of autism should specifically address a child's use of off-topic or noncontingent utterances. To be truly comprehensive, an assessment of this specific area of discourse impairment should be included. Moreover, communicative interventions should target the extinction of noncontingent responses. Studies of mother-child conversations involving children with developmental and language delay (Yoder, Davies, \& Bishop, 1994) and children with autism (Curcio \& Paccia, 1987) have found that mothers are quite skilled at scaffolding and redirecting their child's discourse, even when the child is delayed or disabled. Similarly, Siller and Sigman (2002) found that caregivers of children with autism synchronized their behaviors to their children's attention and activities, and that this parental sensitivity is significantly related to later development of communication skills. It is possible that, within the context of informal play, the parents in our study actually minimized their children's use of off-topic utterances. Future research should examine how these skills may be generalized to more formal education and training of social communication.

\section{ACKNOWLEDGEMENTS}

This research was funded by a grant from the National Institute on Deafness and Other Communication Disorders (PO1/U19 DC 03610), which is part of the NICHD/NIDCD funded Collaborative Programs of Excellence in Autism. The analyses completed were in partial fulfillment of the requirements for a Doctoral degree by the first author. We 
are grateful to Susan Bacalman, Laura Becker, June Chu, Karen Condouris, Anne Gavin, Robert Joseph, Margaret Kjelgaard, Echo Meyer, Jenny Roberts, Jason Smith and Tara Tatelman for their help in collecting and coding the data reported in this paper. We offer special thanks to the children and families who participated in this study.

\section{REFERENCES}

Adams, C., Green, J., Gilchrist, A., \& Cox, A. (2002). Conversational behavior of children with Asperger Syndrome and conduct disorder. Journal of Child Psychology and Psychiatry and Allied Disciplines, 43, 679-690.

American Psychiatric Association. (1994). Diagnostic and Statistical Manual of Mental Disorders (DSM-IV) (4th ed.).Washington, DC: APA.

Baltaxe, C. A. M. (1977). Pragmatic deficits in the language of autistic adolescents. Journal of Pediatric Psychology, 2, 176180.

Baron-Cohen, S. (1988). Social and pragmatic deficits in Autism: Cognitive or affective?. Journal of Autism and Developmental Disorders, 18, 379-402.

Capps, L., Kehres, J., \& Sigman, M. (1998). Conversational abilities among children with autism and children with developmental delays. Autism, 2, 325-344.

Cohen, R. (1960). A coefficient of agreement for nominal scales. Educational and Psychological Measurements, 20, 37-46.

Curcio, F., \& Paccia, J. (1987). Conversations with autistic children: Contingent relationships between features of adult input and children's response adequacy. Journal of Autism and Developmental Disorders, 17, 81-93.

Dunn, L. M., \& Dunn, L. M. (1997). Peabody picture vocabulary test (3rd ed). MN: American Guidance Service Circle Pines.

Elliott, C. D. (1990). Differential ability Scales San Antonio. TX: The Psychological Corporation/Harcourt Brace.

Fine, J., Bartolucci, G., Szatmari, P., \& Ginsberg, G. (1994). Cohesive discourse in pervasive developmental disorders. Journal of Autism and Developmental Disorders, 24, 315330.

Frith, U. (1989). A new look at language and communication in Autism. Autism: Special Issue of British Journal of Disorders of Communication, 24, 123-150.

Geller, E. (1998). An investigation of communication breakdowns and repairs in verbal autistic children. British Journal of Developmental Disabilities, 44, 71-85.

Happé, F. (1994). Autism: An introduction to psychological theory. London: University College London Press.

Hurtig, R., Ensrud, S., \& Tomblin, J. B. (1982). The communicative function of question production in autistic children. Journal of Autism and Developmental Disorders, 12, 57-69.

Kjelgaard, M., \& Tager-Flusberg, H. (2001). An investigation of language profiles in austism: Implications for genetic subgroups. Language and Cognitive Processes, 16, 287-308.

Klin, A., Jones, W., Schultz, R., Volkmar, F., \& Cohen, D. J. (2002). Defining and quantifying the social phenotype in autism. American Journal of Psychiatry, 159, 895-908.

Lord, C., \& Paul, R. (Eds). 1997. In D. J. Cohen, \& F. R. Volkmar (Eds.), Handbook of autism and pervasive developmental disorders (2nd ed., pp. 195-225). New York: John Wiley and Sons.

Lord, C., Risi, S., Lambrecht, L., Cook, E. H., Lenventhal, B. L., DiLavore, P. S., Pickles, A., \& Rutter, M. (2000). The Autism Diagnostic Observation Schedule-Generic: A standard mea- sure of social and communication deficits associated with the spectrum of Autism. Journal of Autism and Developmental Disorders, 30, 205-223.

Lord, C., Rutter, M., \& LeCouteur, A. (1994). Autism diagnostic interview-revised: A revised version of a diagnostic interview for caregivers of individuals with possible pervasive developmental disorders. Journal of Autism and Developmental Disorders, 24, 659-685.

Loveland, K., \& Landry, S. (1986). Joint attention and language in autism and developmental language delay. Journal of Autism and Developmental Disorders, 16, 335-349.

Loveland, K. A., Landry, S. H., Hughes, S. O., \& Hall, S. K. (1988). Speech acts and the pragmatic deficits of Autism. Journal of Speech and Hearing Research, 31, 593-604.

Miller, J., \& Chapman, R. (2000). Systematic analysis of language transcripts (SALT) [Computer software, SALT for Windows, research version 6.1]. Madison, WI: University of Wisconsin, Language Analysis Lab.

Paul, R., \& Cohen, D. J. (1985). Comprehension of indirect requests in adults with autistic disorders and mental retardation. Journal of Speech and Hearing Research, 28, 475479.

Prizant, B., \& Rydell, P. J. (1993). Assessment and intervention considerations for unconventional verbal behavior. In $\mathrm{J}$. Reichle \& D. Wacker (Eds.), Communicative alternatives to challenging behavior: Integrating functional assessment and intervention strategies. Communication and language intervention series. (pp. 263-297). Baltimore, MD: Paul H. Brookes Publishing Co.

Ramberg, C., Ehlers, S., Nyden, A., Johansson, M., \& Gillberg, C. (1996). Language and pragmatic functions in school-age children on the autism spectrum. European Journal of Disorders of Communication, 31(4), 387-413.

Siller, M., \& Sigman, M. (2002). The behaviors of parents of children with autism predict the subsequent development of their children's communication. Journal of Autism and Developmental Disorders, 32, 77-89.

Stone, W. L., \& Caro-Martinez, L. M. (1990). Naturalistic observations of spontaneous communication in autistic children. Journal of Autism and Developmental Disorders, 20, 437-451.

Tager-Flusberg, H. (1996). Current theory and research on language and communication in autism. Journal of Autism and Developmental Disorders, 26, 169-172.

Tager-Flusberg, H. (1999). A psychological approach to understanding the social and language impairments in autism. International Review of Psychiatry, 11, 325-334.

Tager-Flusberg, H. (2000). Understanding the language and communicative impairments in autism. In L. M. Glidden (Ed.), . (pp. 185-205). San Diego: Autism Academic Press.

Tager-Flusberg, H. (2001). A re-examination of the theory of mind hypothesis of autism. In J. Burack, T. Charman, N. Yirmiya, \& P. Zelazo (Eds.), The development of autism: Perspectives from theory and research. (pp. 173-193). NJ: Lawrence Erlbaum Associates Mahwah.

Tager-Flusberg, H., \& Anderson, M. (1991). The development of contingent discourse ability in autistic children. Journal of Child Psychology and Psychiatry, 32, 1123-1134.

Volden, J., \& Lord, C. (1991). Neologisms and idiosyncratic language in autistic speakers. Journal of Autism and Developmental Disorders, 21, 109-131.

Volden, J., Mulcahy, R. F., \& Holdgrafer, G. (1997). Pragmatic language disorder and perspective taking in autistic speakers. Applied Psycholinguistics, 18, 181-198.

Williams, K. T. (1997). Expressive vocabulary test. MN: American Guidance Service Circle Pines.

Yoder, P. J., Davies, B., \& Bishop, K. (1994). Reciprocal sequential relations in conversations between parents and children with developmental delays. Journal of Early Intervention, 18, 362-379. 
Copyright of Journal of Autism \& Developmental Disorders is the property of Springer Science \& Business Media B.V.. The copyright in an individual article may be maintained by the author in certain cases. Content may not be copied or emailed to multiple sites or posted to a listserv without the copyright holder's express written permission. However, users may print, download, or email articles for individual use. 